\title{
SARS-COV-2: SUA RELAÇÃO COM OS ANIMAIS E POTENCIAL DOENÇA ZOONÓTICA
}

\author{
Suzane Manzini ${ }^{1}$ \\ Nássarah Jabur Lot Rodrigues ${ }^{1}$ \\ Thainá Valente Bertozzo ${ }^{1}$ \\ Isabella Neves Aires ${ }^{2}$ \\ Simone Baldini Lucheis ${ }^{1,3}$
}

\begin{abstract}
RESUMO
Os coronavírus (CoVs) estão em constante evolução e representam uma ameaça a saúde pública mundial por causarem surtos que podem ser fatais. Como exemplo, pode-se citar os vírus causadores das síndromes respiratórias SARS e MERS. O novo coronavírus SARSCoV-2 que surgiu em 2019 em Wuhan, na China, é o terceiro surto de CoV em humanos e responsável por causar impactos negativos na saúde, como manifestações respiratórias, digestivas e sistemáticas. Diante da necessidade de maiores estudos acerca desta enfermidade, esta revisão objetivou reunir os dados sobre SARS-CoV-2 em animais, dada a grande probabilidade de salto de espécies associados aos morcegos, e também de estudos que demonstram que o SARS-CoV-2 pode ter tido origem em um reservatório animal, com destaque para os morcegos e pangolins. A vigilância deste microrganismo deve ser direcionada de modo a identificar os reservatórios do SARS-CoV-2 para melhor compreensão da patogênese e seus hospedeiros a fim de aumentar os conhecimentos a respeito deste vírus pandêmico.
\end{abstract}

Palavra-chave: Coronavírus; COVID-19; animais; artigo de revisão.

\section{SARS-COV-2: ITS RELATIONSHIP WITH ANIMALS AND POTENTIAL ZOONOTIC DISEASE}

\begin{abstract}
Coronavirus (CoVs) are constantly evolving and represents a threat to the world's public health since they cause outbreaks that can be fatal. As an example, the viruses that cause SARS and MERS respiratory syndromes can be mentioned. The new SARS-CoV-2 coronavirus that appeared in 2019 in Wuhan, China, is the third CoV outbreak in humans with negative health conditions such as respiratory, digestive and systematic manifestations. In view of the need for further studies on this disease, this review aimed to gather data on SARSCoV-2 in animals, given the high probability of jumping species associated with bats, and also studies that demonstrate that SARS-CoV-2 may have originated in an animal reservoir, more likely on bats and pangolins. The surveillance of this microorganism should be directed to identify the reservoirs of SARS-CoV-2 for a better understanding of the pathogenesis and its hosts in order to increase knowledge about this pandemic virus.
\end{abstract}

Keywords: Coronavírus; COVID-19; animals; review article.

\footnotetext{
${ }^{1}$ Faculdade de Medicina de Botucatu, Departamento de Doenças Tropicais e Diagnóstico por Imagem, Universidade Estadual Paulista "Júlio de Mesquita Filho"(UNESP), Correspondência: suzane.manzini@unesp.br

2 Faculdade de Ciências, Universidade Estadual Paulista "Júlio de Mesquita Filho" (UNESP), Avenida Engenheiro Luiz Edmundo Carrijo Coube, Bauru, Brasil

3 Agência Paulista de Tecnologia e Agronegócio (APTA), Bauru, Brasil simone.lucheis@sp.gov.br
} 


\section{SARS-COV-2: SU RELACIÓN CON LOS ANIMALES Y LA ENFERMEDAD ZOONÓTICA POTENCIAL}

\section{RESUMEN}

Los coronavirus $(\mathrm{CoV})$ evolucionan constantemente y representan una amenaza para la salud pública en todo el mundo porque causan brotes que pueden ser fatales. Como ejemplo, podemos mencionar los virus que causan los síndromes respiratorios SARS y MERS. El nuevo coronavirus SARS-CoV-2 que surgió en 2019 en Wuhan, China, es el tercer brote de $\mathrm{CoV}$ en humanos y es responsable de causar impactos negativos en la salud, como manifestaciones respiratorias, digestivas y sistemáticas. En vista de la necesidad de más estudios sobre esta enfermedad, esta revisión tuvo como objetivo recopilar datos sobre el SARS-CoV-2 en animales, dada la alta probabilidad de especies saltarinas asociadas con los murciélagos, y también estudios que demuestren que el SARS-CoV-2 es puede haberse originado en un reservorio animal, especialmente murciélagos y pangolines. La vigilancia de este microorganismo debe estar dirigida a identificar los reservorios del SARS-CoV-2 para una mejor comprensión de la patogénesis y sus hospedadores con el fin de aumentar el conocimiento sobre este virus pandémico.

Palabra clave: Coronavirus; COVID-19; animales; artículo de revisión.

\section{INTRODUÇÃO}

O aumento no comércio e viagens, mudanças climáticas, patógenos em rápida evolução, explosão populacional, mudança de hábitos e estilo de vida de humanos, criação intensiva de animais integrados e outros inúmeros fatores são grandes ameaças para que zoonoses emergentes e reemergentes cresçam no mundo. Dentro das zoonoses, há as doenças infecciosas causadas por vírus, bactérias, protozoários, fungos e príons que estão associadas a fatores ambientais e à animais para se tornarem doenças emergentes (1).

Os patógenos causadores de doenças infecciosas sofrem mutações e passam pelo salto de espécies, que permite que eles se adaptem e tenham as condições ambientais favoráveis para se reproduzirem no organismo humano. Como exemplo disso, pode-se citar a Síndrome Respiratória Aguda Grave (SARS), Síndrome Respiratória do Oriente Médio (MERS) e atualmente as Doenças do Coronavírus 2019 (COVID-19), causada pelo Coronavírus SARS-2 ou mais comumente conhecida, SARS-CoV-2 (1).

Os coronavírus (CoVs) estão em constante evolução, grandes exemplos destes foram o SARS e MERS, síndromes respiratórias que resultaram em surtos fatais, representando uma ameaça a saúde pública no mundo. O novo coronavírus, SARS-Cov-2, que surgiu em 2019, é considerado o terceiro surto de $\mathrm{CoV}$ em humanos. A COVID-19 surgiu em Wuhan na província de Hubei, na China, em dezembro de 2019, trazendo consigo agravos negativos à saúde humana, como manifestações respiratórias, digestivas e sistêmicas (2).

O SARS-CoV-2 é um vírus de RNA e sua transmissão ocorre de pessoa para pessoa por meio de partículas e gotas transportadas pelo ar, infectando pneumócitos tipo 2 e células epiteliais brônquicas ciliadas, utilizando, para isso, receptores de Enzima Conversora da Angiotensina 2 - ACE2 (1).

Os coronavírus pertencem à ordem Nidovirales, família Coronaviridae e subdivididas em duas subfamílias Torovirinae e Orthocoronaviridae. Este último é composto pelos gêneros Alfacoronavirus e Betacoronavirus, que infectam mamíferos e Gamacoronavirus, Deltacoronavirus que infectam tanto aves quanto mamíferos. O SARS-CoV-2 é um betacoronavírus (3).

Manzini S, Rodrigues NJL, Bertozzo TV, Aires IN, Lucheis SB. SARS-COV-2: Sua relação com os animais e potencial doença zoonótica. Vet. e Zootec. 2021; v28: 001-013. 
A forma clínica varia entre espécies. Bovinos, equinos e suínos podem apresentar casos de enterite. Outro sintoma relatado em bovinos é a doença do trato respiratório superior, que também pode ser observada em cães, felinos e aves. Já em humanos, pode-se notar resfriados comuns até infecções respiratórias altamente fatais (4).

Diante da necessidade de maiores estudos acerca desta enfermidade, seu respectivo agente etiológico e possíveis animais hospedeiros, esta revisão objetivou reunir os dados sobre SARS-CoV-2 em animais, disponíveis desde o início da pandemia no PubMed, Google Scholar e sites de organizações de saúde humana e animal como o Centro de Controle e Prevenção de Doenças (CDC).

\section{REVISÃO}

\section{Classificação do coronavírus}

Coronavírus são vírus de RNA que possuem diâmetro entre $60 \mathrm{~nm}$ a 140nm. Recebem este nome por possuírem projeções em sua superfície que lhes conferem a aparência de uma coroa quando vistos sob microscopia eletrônica. O primeiro relato destes vírus foi datado de 1966 por Tyrell e Bynoe (3).

Os coronavírus (CoVs) pertencem à ordem Nidovirales, subordem Coronidovirineae, família Coronaviridae e subdivididas em duas subfamílias Torovirinae e Orthocoronaviridae. Este último é composto pelos gêneros alfa $(\alpha)$, beta $(\beta)$, gama $(\gamma)$ e delta $(\delta)$, que corresponde aos grupos um a quatro (I a IV), respectivamente. Os Alphacoronavirus $(\alpha)$ e Betacoronavirus ( $\beta$ ) são responsáveis por infectarem os mamíferos e têm provável origem em morcegos, enquanto os Gammacoronavirus $(\gamma)$ e Deltacoronavirus $(\delta)$ infectam aves, peixes e mamíferos e presume-se que sejam de origem suína. O SARS-CoV-2 pertence ao gênero Betacoronavirus, bem como o SARS-CoV e MERS-CoV, e subgênero Sarbecovirus (4).

Baseada em análise de sequências, relação filogenética e exame sorológico (3), foi encontrado que o SARS-CoV-2 tem de 88 a $89 \%$ de similaridade a dois coronavírus de origem de morcego (bat-SL-CoVZC45 e bat-SL-CoVZXC21, também conhecidos como ZC45 e ZXC21), no entanto possui $82 \%$ de similaridade ao SARS-CoV humano Tor2 e BJ01 2003. Comparando o SARS-CoV-2 com os já conhecidos SARS-CoV e MERS-CoV, o novo vírus teve $50-51,8 \%$ de identidade com o primeiro e $79 \%$ com o segundo (4).

Cada coronavírus é responsável por infectar uma única espécie hospedeira animal quando em condições naturais e a transmissão interespécies ocorre raramente. São capazes de causarem infecções nos tratos respiratório e/ou digestivo, e poucos deles tem a capacidade de se espalhar pelos rins, fígado ou sistema nervoso central. Alguns CoVs são endêmicos em animais domésticos em diferentes países (5).

Os principais reservatórios de coronavírus são morcegos e aves, no entanto os novos CoVs estão se diversificando. Já houve relatos de Gamacoronavirus e Deltacoronavirus em pássaros selvagens e domésticos como gansos, pombos e patos (5). Além disso, já foi demonstrado que bovinos, suínos, perus, camelos, camundongos, cães, gatos, furões e martas são considerados reservatórios deste vírus (6).

Os $\mathrm{CoVs}$ que mais comumente infectam os animais são gamacoronavírus $(\gamma-\mathrm{CoV})$ causador da bronquite infecciosa em galinhas (IBV); alfacoronavírus $(\alpha-\mathrm{CoV})$ que provoca gastroenterite transmissível em suínos (TGEV); betacoronavírus $(\beta-\mathrm{CoV})$ que origina a encefalomielite hemaglutinante em suínos (HEV); $\beta-\mathrm{CoV}$ de diarréia epidêmica porcina em suínos (PEDV); $\beta$-Co de bovino (BCoV); alfacoronavírus ( $\alpha-\mathrm{CoV})$ entérico canino (CECoV), $\beta-\mathrm{CoV}$ respiratório canino $(\mathrm{CRCoV}) ; \alpha-\mathrm{CoV}$ felino em gatos $(\mathrm{FCoV}) ; \mathrm{e} \beta-\mathrm{CoV}$ da hepatite murina em camundongos (MHV) $(4,5)$.

Manzini S, Rodrigues NJL, Bertozzo TV, Aires IN, Lucheis SB. SARS-COV-2: Sua relação com os animais e potencial doença zoonótica. Vet. e Zootec. 2021; v28: 001-013. 


\section{Histórico do Coronavírus (CoV)}

Os primeiros coronavírus humanos $(\mathrm{HCoV})$ foram isolados em 1937, através da análise de secreções nasais de pacientes com resfriado comum em Londres, Inglaterra. Entretanto foi em 1965 que o vírus foi descrito como coronavírus, devido a sua forma física parecer uma coroa, quando visto por microscopia. Deste ano até 2002 foram relatados quatro subtipos de coronavírus que infectaram o ser humano, sendo dois $\alpha$-coronavírus (229E e NL63), e dois $\beta$ coronavírus (OC43 e HKU1) que acarretam infecções comuns na maioria das pessoas, sendo as crianças as mais propensas a se infectarem. De maneira geral, as infecções destes quatros subtipos produzem infecções não complicadas no trato respiratório superior e/ou inferior $(6,7)$.

Foi em 2002 que surgiu o SARS-CoV, causador da Síndrome Respiratória Aguda Grave (Severe Acute Respiratory Syndrome - SARS), com potencial letal aos humanos. O vírus foi identificado na província de Guangdong, na China. SARS-CoV se espalhou por 29 países, atingindo pelo menos 8.096 indivíduos, com 774 óbitos. A China foi o país com maior número de casos (5.327) e de óbitos (349). Fora da Ásia, o país com números mais expressivos foi o Canadá, com 251 casos e 43 óbitos (6).

Em 2012, surge o MERS-CoV que originou a Síndrome Respiratória do Oriente Médio (Middle East Respiratory Syndrome - MERS). O novo betacoronavírus não havia sido detectado em humanos até então e foi identificado pela primeira vez num indivíduo na Arábia Saudita. Esse vírus infectou cerca de 2.494 indivíduos, confirmado por exames laboratoriais, em 27 países, com 858 óbitos até novembro de 2019 (6).

Em dezembro de 2019 um novo betacoronavírus foi identificado na China, em Wuhan, na província de Hubei quando um grupo de pessoas deu entrada no pronto socorro na cidade com o quadro de pneumonia desconhecida. Amostras de células epiteliais das vias respiratórias desses pacientes foram isoladas e submetidas a técnica de sequenciamento imparcial, e no dia 07 de janeiro de 2020 foi chamado de 2019-nCoV (5).

Em fevereiro, a Organização Mundial da Saúde - OMS - nomeou a doença de Doença do Coronavírus-2019 (Coronavirus Disease 2019 - COVID-19). O Comitê Internacional de Taxonomia de Vírus (ICTV) oficializou a nomenclatura do vírus como SARS-CoV-2. Em 29 de fevereiro, a OMS declarou a doença como COVID-19 e o agente causador como SARSCoV-2 (5).

No dia 13 de janeiro de 2020, foi confirmado o primeiro caso fora da China, na Tailândia. Nos meses seguintes, até o início de junho de 2020, a COVID-19 apresentou milhões de casos confirmados e levou à óbito milhares de pacientes em todo o mundo, por mais de 215 países. Em 11 de março, foi declarada pandemia, sendo esta a primeira pandemia conhecida causada por um coronavírus. No Brasil, o primeiro caso da doença foi confirmado no dia 26 de fevereiro e a primeira morte ocorreu no dia 16 de março de 2020 (6).

Os relatos da origem da COVID-19 em Wuhan, na China, estão diretamente relacionados com o Mercado Atacadista de Frutos do Mar de Huanan. Por haver comercialização de animais vivos e devido ao alto número de indivíduos infectados neste local, surge a hipótese de uma via de transmissão zoonótica do vírus (7).

\section{Epidemiologia}

\section{Coronavírus em humanos}

Há quatro tipos de coronavírus que causam infecções no ser humano (HCoVs) que são os HCoV-E299 ( $\alpha$-CoV), HCoV-NL63 ( $\alpha$-CoV), HCoV-OC43 $(\beta-C o V)$ e HCoV-HKU1 ( $\beta$ $\mathrm{CoV})$. As infecções causadas por esses coronavírus são consideradas leves e seus sintomas são como os resfriados comuns, porém em jovens, idosos e pessoas imunocomprometidas, as

Manzini S, Rodrigues NJL, Bertozzo TV, Aires IN, Lucheis SB. SARS-COV-2: Sua relação com os animais e potencial doença zoonótica. Vet. e Zootec. 2021; v28: 001-013. 
infecções provocadas pelos $\mathrm{HCoVs}$ atingem o trato respiratório inferior (LRTIs). Atualmente, os coronavírus que acometem as LRTIs são o SARS, MERS e SARS-CoV-2 (5).

Os CoVs NL63 e HKU1 foram descobertos em 2003, posteriormente ao SARS-CoV, embora estivessem circulantes em diversos países há mais de 100 anos. O HCoV-OC43 e o BCoV bovino possuem $95 \%$ de compatibilidade genética, o que indica uma transmissão zoonótica de bovinos para humanos, mas o contrário não ocorre, ou seja, o humano não transmite para o bovino. A transmissão acontece pela ocorrência de uma deleção de 290 nucleotídeos no vírus humano (HCoV-OC43), mutação que estava ausente no $\mathrm{BCoV}$, sugerindo mudanças adaptativas após saltar a barreira da espécie bovina para os humanos (5).

Alguns animais estão vulneráveis ao SARS-CoV-2 por ter o receptor da Enzima Conversora da Angiotensina 2 (ACE2) conservado em mamíferos (8).

A principal via de transmissão do SARS-CoV-2 é de humano para humano através de gotículas respiratórias, fezes e urinas de infectados (9). O vírus pode ficar incubado de dois a quatorze dias e pode ser transmitido para outras pessoas antes mesmo dos primeiros sintomas aparecem. Os sintomas mais comuns são febre, fadiga e tosse seca. A doença afeta o sistema respiratório que, em casos mais graves, compromete a capacidade respiratória do indivíduo, necessitando de cuidados médicos intensivos (10).

No entanto, devido ao pouco conhecimento do mecanismo de transmissão da COVID19 há dificuldade no desenvolvimento de protocolos de controle contra a transmissão da infecção entre os pacientes (9).

\section{Coronavírus em animais}

É aceito que o SARS-CoV-2 tem origem animal, embora não haja certeza do surgimento de sua transmissão. O que se sabe é que os morcegos são reservatórios do SARS$\mathrm{CoV}$, MERS e de diversos CoV. Diante isso, é mais provável que o morcego seja o atual reservatório do SARS-CoV-2, visto que era geneticamente próximo do SARS do morcego ferradura, com $96 \%$ de similaridade (4).

De acordo com a Organização Mundial da Saúde, animais de pacientes infectados com a COVID-19 podem adquirir a doença devido ao contato próximo com o humano infectado (9).

A partir da testagem de amostras de morcegos na China, há chances de identificarem mais cepas que possivelmente estejam relacionadas ao SARS-CoV-2. Ademais, outros animais podem estar envolvidos como hospedeiros intermediários e possível fonte de transmissão aos humanos (5).

Dada a dificuldade de transmissão direta de vírus de morcego aos humanos, eles precisam de um hospedeiro intermediário para se espalhar para os humanos e causar doenças. Nos casos de SARS e MERS, o patógeno foi transmitido a humanos por meio da exposição a gatos civetas do Himalaia (Pagumalarvata) e camelos dromedários (Camelus dromedarius). Para o SARS-CoV-2 sugere-se que originou de morcegos e foi transmitido a outros hospedeiros animais e, em última caso, aos humanos (2).

\section{Animais Silvestres}

Um relatório feito em abril de 2020 notificou que um tigre de quatro anos do zoológico de Nova York, Bronx, teve sintomas clínicos de SARS-Cov-2 como sinais respiratórios (tosse seca) após o contato com ser humano. $\mathrm{O}$ vírus foi detectado em amostras do trato respiratório. Desta forma, estudo feitos sugerem que os felinos selvagens são mais suscetíveis para a COVID-19, por serem capazes de apresentar a doença clínica; no entanto, a transmissão animal a animal considera-se fraca, pois outros tigres e animais co-alojados tiveram 
resultados negativos. Sugere-se que a infecção tenha sido adquirida por um tratador com infecção assintomática (9).

Além dos tigres, três leões africanos do Zoológico do Bronx, Nova York, testaram positivo em abril de 2020, os quais apresentaram sinais clínicos respiratórios, como tosse seca e inapetência. A infecção provavelmente foi adquirida de um tratador infectado, mas assintomático (5). O mesmo cenário envolvendo três tigres malaios foi relatado em 12 de outubro de 2020, em um zoológico em Knox, Tennessee, que inicialmente apresentaram tosse leve, letargia e inapetência, porém todos os tigres se recuperaram gradativamente (2).

Em abril de 2020, na Holanda, os visons de duas fazendas distintas desenvolveram distúrbios respiratórios e gastrointestinais. Os visons foram necropsiados e a maioria apresentou lesões pulmonares como pneumonia intersticial. Posteriormente, na biologia molecular foi detectado o RNA viral em amostras de pulmão, swab de garganta, swab retal e fígado. Como alguns trabalhadores já haviam testado positivo para o SARS-CoV-2, sugere-se a transmissão de homem para animal (11).

Em outubro de 2020, 62 fazendas de visons foram infectadas na Holanda. Quarenta e três estavam localizadas na província de Noord Brabant, 17 na província de Limburg e dois em Gelderland. Em 25 fazendas, os proprietários notaram sinais clínicos compatíveis com COVID-19 (11).

Atualmente, os humanos continuam sendo a fonte mais provável de disseminação do SARS-CoV-2 entre as fazendas, portanto, medidas adicionais foram tomadas para controlar a transmissão. Isto é, o governo holandês decidiu preparar uma legislação para acabar com a criação de visons na Holanda em março de 2021, antes do novo período de reprodução. Esta decisão tem como objetivo evitar o estabelecimento de um reservatório permanente na indústria de vison e um maior risco para a saúde pública, situação que ocorreria se a infecção pelo SARS-CoV-2 se espalhasse em mustelídeos selvagens e outras espécies. Como pode ser visto na literatura, todos os surtos de SARS-CoV-2 em visons ocorreram em países europeus ou nos Estados Unidos. Os visons foram os primeiros animais de criação intensiva a vivenciar surtos de COVID-19, parecendo ser uma espécie muito suscetível ao SARS-CoV-2 (2).

Um estudo feito no Harbin Veterinary Research Institute, que foi inoculado duas cepas do vírus do SARS-CoV-2 em furões, descobriram que este animal é suscetível ao vírus (12). Enquanto alguns furões foram assintomáticos, outros apresentaram febre, perda de apetite e problemas no trato respiratório. O RNA viral foi detectado na concha nasal, palato mole e amígdalas de todos os furões inoculados com esses dois vírus, mas não foram detectados em nenhum outro órgão testado. Os resultados indicam que o SARS-CoV-2 pode se replicar no trato respiratório superior de furões por até 8 dias sem causar doença grave ou morte (12).

Outro estudo conduzido no Friedrich-Loeffler-Institut (FLI), Alemanha, mostrou que o SARS-CoV-2 pode replicar-se e ser transmitido com eficiência para furões coalojados, sem estes apresentarem sinais clínicos. O RNA viral foi detectado nas lavagens nasais e, em menor grau, nos esfregaços retais obtidos de furões inoculados e em contato. Além disso, o RNA viral foi detectado no trato respiratório, intestino, músculo, pele, nódulo linfático, glândula adrenal e/ou tecidos cerebrais em furões inoculados eutanasiados. Todos os furões inoculados e alguns coalojados desenvolveram anticorpos contra SARS-CoV-2. Contudo, o fato de que o SARS-CoV-2 se replica eficientemente no trato respiratório superior de furões, torna-os um candidato como modelo animal para avaliar a eficácia de medicamentos antivirais ou vacinas contra COVID-19. Eles mimetizam os sinais clínicos leves de SARS-CoV-2, lesões pulmonares e transmissão em humanos (13). Além disso, a suscetibilidade dos furões ao SARS-CoV-2 permanece obscura devido a semelhanças na arquitetura do trato respiratório entre furões e humanos, o que fundamenta ainda mais os furões como um animal modelo adequado para pesquisas relacionadas ao COVID-19 (2).

Manzini S, Rodrigues NJL, Bertozzo TV, Aires IN, Lucheis SB. SARS-COV-2: Sua relação com os animais e potencial doença zoonótica. Vet. e Zootec. 2021; v28: 001-013. 
Musaranhos, da espécie Tupaia belangeri, machos e fêmeas foram infectados experimentalmente com SARS-CoV-2 via intranasal e foi visto que a maioria das fêmeas apresentaram aumento da temperatura corporal, sem apresentar sinais clínicos ou lesões macroscópicas (14). O RNA viral foi detectado em animais mais jovens por até 12 dias pósinfecção (dpi) em amostras nasais, garganta, anal e amostras de sangue. O RNA foi detectado em diferentes órgãos, incluindo pulmões, pâncreas e útero. Embora leves, as alterações patológicas foram observadas principalmente nos pulmões e em menor extensão no baço, intestino, cérebro, fígado e coração. Não foram observados sinais clínicos em musaranhos arbóreos inoculados com SARS-CoV-2, com exceção do aumento da temperatura corporal (acima de $39^{\circ} \mathrm{C}$ ). Os resultados encontrados confirmam que este animal não é suscetível a infeção pelo SARS-CoV-2 (14).

A suscetibilidade de morcegos frugívoros egípcios (Rousettus aegyptiacus) foram estudados através da inoculação do SARS-CoV-2 alemão via intranasal nesses animais (13). Os morcegos não apresentaram sintomas clínicos e excretaram vírus via oral por até $12 \mathrm{dpi}$. O RNA viral foi detectado em tecidos respiratórios e em níveis mais baixos no coração, pele e intestino. Anticorpos contra SARS-CoV-2 foram detectados em morcegos inoculados e de contato. O RNA viral foi detectado em morcegos coalojados por até 21 dpi, indicando transmissão bem-sucedida de morcego para morcego. Estes resultados sugerem que os morcegos desempenham função na replicação e transmissão do SARS-CoV-2 (13).

Ademais, os morcegos são hospedeiros reservatórios ideais para CoVs, já que voam pelas florestas em busca de alimento e podem transmitir o vírus a uma variedade de hospedeiros com os quais entram em contato, e ainda que contraiam o vírus, ficam assintomáticos. Com a pandemia da COVID-19, descobertas laboratoriais confirmaram que o SARS-CoV-2 também é $96 \%$ idêntico ao CoV do morcego no nível genômico e, portanto, os morcegos podem ser a principal fonte desse transbordamento zoonótico (4).

Em amostras de pulmões, intestino e sangue de pangolins em 2017/2018 foram identificados diversos CoVs, e após análise da sequência genética, foi detectado que esses coronavírus pertenciam a duas linhagens diferentes, sendo que uma dessas linhagens compartilhava 97,4\% de identidade de aminoácidos SARS-CoV-2 (5).

$\mathrm{O} \mathrm{CoV}$ também foi isolado dos pangolins malaios, e o RBD na proteína $\mathrm{S}$ do SARSCoV-2 era muito semelhante ao do Pangolin-CoV e, portanto, os pangolins podem ser hospedeiros intermediários do SARS-CoV-2 (4). Um grupo de $\beta-\mathrm{CoV}$ encontrados em pangolins compartilharam cerca de $85-92 \%$ de homologia de sequência de nucleotídeos com SARS-CoV-2, sendo o segundo mais próximo em relação ao SARS-CoV-2 após o morcego CoV RaTG13 (2). Especula-se que o ACE2 dos pangolins pode apresentar melhor afinidade para o SARS-CoV-2, uma vez que os $\beta$-CoVs dos pangolins contêm todas as seis mutaçõeschaves que se acredita formarem a ligação ao receptor ACE2 (2).

A ACE2 de serpentes perdeu a capacidade de se associar à proteína $\mathrm{S}$, portanto, não são considerados como um potencial hospedeiro intermediário (15).

As tartarugas são répteis improváveis de adquirirem a infecção, pois todos os hospedeiros conhecidos para $\mathrm{CoV}$ são animais homeotérmicos. Além disso, eles analisaram os aminoácidos correspondentes na ACE2 de tartarugas e concluíram que esta espécie não tem a capacidade de se ligar à proteína S do SARS-CoV-2 (15).

Os cães-guaxinim (Nyctereutes procyonoides) são suscetíveis ao SARS-CoV-2 e podem transmitir o vírus aos animais de contato, pois seis dos nove animais que sofreram a inoculação do vírus via intranasal, desenvolveram uma infecção considerável. Já a transmissão do vírus por contato, aconteceu em dois dos três animais que estavam próximos. Também foram relatados nesses animais a presença do RNA viral em esfregaços nasais e orofaríngeos e o desenvolvimento da resposta imune específica ao SARS-CoV-2. Assim, os

Manzini S, Rodrigues NJL, Bertozzo TV, Aires IN, Lucheis SB. SARS-COV-2: Sua relação com os animais e potencial doença zoonótica. Vet. e Zootec. 2021; v28: 001-013. 
cães-guaxinim são hospedeiros intermediários com potencial para o SARS-CoV-2 e os autores enfatizam que esses animais são de risco referente a transmissão viral (16).

\section{Animais Domésticos}

Em Hong Kong, 27 cães ficaram em vigilância e dois testaram positivo para o SARSCoV-2. A primeira identificação foi feita em fevereiro de 2020 em amostra de swabs da cavidade nasal e oral de um cão de 17 anos. O título do vírus foi baixo nas amostras de cães e não foram observados sinais clínicos. Como o dono havia testado positivo para o vírus, sugere-se a transmissão do humano para o cão $(2,9)$.

O segundo cão foi identificado em março de 2020, relatando-se a infecção de um cão de 2,5 anos de idade, em Hong Kong, após contato com o tutor infectado, sendo o cão assintomático (9).

$\mathrm{Na}$ França, não foram identificados RNA viral e anticorpos em cães que ficaram expostos ao SARS-CoV-2, pois estavam juntos com os estudantes de veterinária infectados pelo vírus. O mesmo ocorreu na Espanha, não se tendo identificado o RNA viral em 12 cães, mesmo estando confinados com pessoas infectadas. Esses relatos sugerem novamente que os cães não têm função na disseminação do COVID-19 (5).

Cães da raça Beagle foram infectados experimentalmente com SARS-CoV-2 e posteriormente foram coletados swabs orofaríngeos e retais de cada animal. Os animais só foram positivos aos swabs retais e quando foram eutanasiados, não foi detectado o RNA viral em nenhum órgão ou tecido. Estes resultados indicam a baixa suscetibilidade dos cães para o SARS-CoV-2 (12).

Em felinos domésticos detectou-se anticorpos pela técnica de ELISA em Wuhan, China, após o surto entre janeiro e março de 2020. Três gatos que tiveram titulação alta pertenciam a três pacientes com a COVID-19, o que indicou uma possível transmissão direta de humano para o gato, ao invés da transmissão de gato para gato. Em Hong Kong, foi detectado o RNA viral em cavidade oral e amostras de esfregaço nasal de um gato assintomático, o qual o tutor estava com a infecção e os restantes 14 gatos da família foram negativos ao SARS-CoV-2. Já na Bélgica, foi detectado SARS-CoV-2 nas fezes e vômito de um gato com sinais clínicos digestivos e respiratórios, e o tutor do animal estava com a infecção (12).

Em abril de 2020, em Nova York nos EUA, dois gatos foram confirmados positivos em dois locais diferentes. Ambos os animais estavam com sinais respiratórios leves. Na Espanha, um para cada oitos gatos testou positivo para o RNA viral do SARS-CoV-2 em esfregaços nasais entre abril e maio de 2020. As descobertas na literatura sugerem que os gatos de estimação são mais suscetíveis do que os cães para o SARS-CoV-2, por eles desenvolverem sintomas leves e excretar o vírus. No entanto, ainda não há clareza se os gatos desempenham uma função na transmissão do vírus para humanos ou outros animais (2).

Gatos foram infectados experimentalmente com SARS-CoV-2 e foram analisadas as fezes desses animais. Foi verificado o RNA viral nas fezes e após a eutanásia foi visto o RNA viral na concha nasal bem como no palato mole, amígdalas, traqueias, pulmões e intestino delgado. A detecção do RNA viral indica que a transmissão ocorreu por gotículas respiratórias. Esses resultados indicam que o SARS-CoV-2 pode se replicar com eficiência em gatos e que os gatos mais jovens são mais vulneráveis do que os mais velhos. Essas descobertas mostram que o vírus é transmissível entre gatos por via aérea (12).

É precipitado dizer que os felinos possam ser hospedeiros intermediários na transmissão da COVID-19 (9), mas segundo relatório da Organização Mundial de Saúde Animal (2020), há casos isolados de cães e gatos domésticos que testaram positivo para a COVID-19 após contato com humano infectado. Entretanto, estudos preliminares relataram que não há evidências que os animais domésticos desempenham alguma função na disseminação da

Manzini S, Rodrigues NJL, Bertozzo TV, Aires IN, Lucheis SB. SARS-COV-2: Sua relação com os animais e potencial doença zoonótica. Vet. e Zootec. 2021; v28: 001-013. 
doença para os seres humanos, por isso o que se recomenda é que pessoas infectadas com o vírus limitem o contato com seus animais e mantenham medidas de higiene $(2,9)$.

\section{Animais de Produção}

A suscetibilidade de porcos (Sus scrofa domesticus), galinhas (Gallus gallus domesticus), patos (Anas platyrhynchos domesticus), perus selvagens (Meleagris gallopavo), codornas japonesas (Coturnix japonica) e gansos africanos (Anser cygnoides) ao SARS-CoV2 foram examinadas e, como resultado, esses animais não podem ser infectados produtivamente pelo SARS-CoV-2 sob as condições experimentais utilizadas em seu trabalho (12). Todos esses animais foram soronegativos para SARS-CoV-2 quando testados por ELISA com soros coletados no dia 14 pós infecção (p.i.) $(12,17)$.

A suscetibilidade de bovinos (Bos taurus) ao SARS-CoV-2 foi estudada e avaliaram que, dois dos seis bezerros Holstein Friesian machos inoculados pareciam estar infectados, por exibirem o RNA viral em swabs nasais e soroconversão específica. Os resultados mostraram que o SARS-CoV-2 tem baixa replicação em bovinos, portanto não são consideráveis suscetíveis ao vírus (18).

\section{Animais de Experimentação}

Os primatas não humanos (NHP) são considerados o padrão ouro para estudar vírus emergentes em humanos e o comportamento perante diversas doenças (10); no entanto, eles são caros e difíceis de manusear, e por questões éticas não são a primeira opção para estudos. Deste modo, tendo em vista que os animais pequenos são mais fáceis de manuseio, mais baratos e disponíveis comercialmente no mundo, são preferenciamente usados para avaliar a virulência e a patogênese de diferentes microrganismos, incluindo o SARS-CoV-2.

Em humanos, camundongos, furões e hamsters o SARS-CoV-2 é mais suscetível do que o MERS-CoV. Desta forma, os modelos de animais abaixo foram estudados para avaliar a virulência e a patogênese de diferentes isolados de SARS-CoV-2 de diferentes países (5).

Foi inoculado em macaco-rhesus (Macaca mulatta) o RNA viral pelas vias intratraqueal, intranasal, ocular e oral. Os macacos mostraram uma elevação na temperatura corporal, perda de peso corporal, alterações no padrão respiratório, diminuição do apetite, postura arqueada, aparência pálida e desidratação. Foram observados infiltrados pulmonares e pneumonia intersticial em exames pós morte. O RNA viral foi detectado no nariz, garganta, pulmões (trato respiratório no geral) e amostras anais por até 17 dpi. No sangue e na urina não foi encontrado o RNA viral (19).

Num outro estudo utilizando macaco-rhesus entre três a cinco anos, houve inoculação do SARS-CoV-2 pela via intratraqueal desses macacos que também resultou na perda de peso corporal, inapetência transitória, taquipneia e postura curvada. O RNA viral foi detectado no nariz, pulmão, intestino, medula espinhal, coração, músculo esquelético e bexiga. A necropsia revelou pneumonia intersticial leve à moderada. Os anticorpos contra o SARS-CoV-2 foram detectados em soros entre 14 a 28 dpi. Após os 28 dias da infecção, os macacos foram infectados com o vírus, no entanto, não houve elevação nos títulos de anticorpos, significando proteção total contra reinfecção nesses animais. Vale ressaltar que os macacos-rhesus estão sendo usados para a avaliação de vacinas inativadas contra a SARS-CoV-2. Esses dados confirmam que os macacos-rhesus são um modelo animal fiel para estudar a patogênese e a eficácia da vacina contra SARS-CoV-2 $(20,21)$, pois nesta espécie, quando adquiriram a infecção primária de SARS-CoV-2, não puderam ser reinfectados com a cepa idêntica durante seu estágio de recuperação inicial devido à imunidade humoral estimulada pela infecção primária (2). 
Os camundongos selvagens e transgênicos estão servindo de modelos em estudos para o SARS-CoV-2. Os estudos mostraram que o vírus tem uma ligação para receptores ACE2 humanos (hACE2) e uma ligação limitada para ACE2 murino (22).

Num estudo, camundongos transgênicos expressando receptores hACE2 para o SARSCoV-2 foram usados. A inoculação intranasal de camundongos WT-HB-01 e camundongos hACE2 livres de patógenos específicos de 6-11 meses de idade com SARS-CoV-2 foi realizada. Como resultado, somente camundongos transgênicos hACE2 exibiram cerdas leves e perda de peso em até $8 \%$; lesões pulmonares e alterações histológicas como pneumonia e infiltração de células inflamatórias e imunológicas foram descritas. Não foram observadas alterações histológicas notáveis ou antígenos virais no miocárdio, fígado, baço, rim, cérebro, intestino e testículo. Como pré-tratamento de camundongo foi usado soro de paciente convalescente humano com SARS-CoV-2 e houve redução das cargas virais nos pulmões. Assim sendo, esses achados na literatura indicam que os camundongos transgênicos, podem desempenhar uma função importante no estudo da imunopatologia da COVID-19 (5).

Outros estudos que utilizaram hamsters descreveram a infecção por SARS-CoV-2. No primeiro estudo, foram inoculados via intranasal o SARS-CoV-2 de um paciente em Hong Kong em hamsters sírios dourados, de 6 a 10 semanas de idade. Inicialmente os animais desenvolveram sinais clínicos dentro de uma semana como letargia, pelo arrepiado, postura arqueada para trás, taquipneia e perda de peso corporal. A carga viral estava elevada nos pulmões e em níveis mais baixos no intestino, glândulas salivares, coração, fígado, baço, nódulos linfáticos, rim, cérebro e sangue. Os hamsters se recuperaram em 14 dpi e apresentaram anticorpos neutralizantes séricos elevados em 7 e 14 dpi. Após eutanásia, revelaram alterações patológicas na concha nasal, traqueia e pulmões, incluindo consolidação pulmonar e hemorragia pulmonar grave (23).

Hamsters sírios dourados foram infectados experimentalmente com SARS-CoV-2 e foi detectado RNA viral de 2 a 14 dpi, sendo a maior carga viral nos pulmões e em níveis menores nos rins e amostras de fezes. Após 7 dpi foram observados a eliminação viral e o reparo de tecido. Todos os hamsters se recuperaram e os anticorpos neutralizantes foram detectados em 14 dpi. O vírus é transmitido de forma eficiente dos hamsters inoculados para hamsters ingênuos coalojados. Isso evidencia que os hamsters são um modelo animal valioso para estudar a patogênese, imunopatologia e transmissão da SARS-CoV-2 (24).

O hamster dourado ou sírio (Mesocricetus auratus) é considerado um animal modelo para estudar a transmissão, patogenicidade da doença, tratamento e vacinação para o SARSCoV-2, uma vez que o ACE2 do hamster poderia se associar com alta afinidade ao SARS-CoV-2 (2).

Considerando que o SARS-CoV-2 impacta negativamente os idosos, foi feito um estudo para investigar se o mesmo acontecia em hamsters e evidenciaram que a replicação viral no trato respiratório superior e inferior era independentemente da idade dos animais, mas que a perda de peso foi mais visível nos animais mais velhos e a recuperação pulmonar foi mais rápida nos hamsters mais jovens (22).

Em amostras de um porquinho da índia e dois coelhos que conviviam com seres humanos confirmados para a COVID-19 na Espanha, entre abril e maio de 2020, não foi detectado o RNA viral, sugerindo a não suscetibilidade desses animais para o SARS-CoV-2 (5).

De maneira geral, Mullick et al. (19) citam que o fator limitante para usar animais comuns de experimentação como camundongos, ratos, coelhos e porquinhos da índia para estudos sobre o SARS-CoV-2, é devido ao fato de que esses animais não têm receptores ACE2 sensíveis a ligação do vírus causador da COVID-19.

Assim sendo, o alinhamento de proteínas e a análise filogenética da proteína ACE2 macaco símio (Macaca mulatta) e chimpanzé (Pan troglodytes) são os mais próximos de

Manzini S, Rodrigues NJL, Bertozzo TV, Aires IN, Lucheis SB. SARS-COV-2: Sua relação com os animais e potencial doença zoonótica. Vet. e Zootec. 2021; v28: 001-013. 
ACE2 humano com 94,9 a 99\% de identidade de sequência (8). Posteriormente, a sequência mais próxima é do gato doméstico (Felis catus) com 85,2\% de identidade total em comparação com ACE2 humano. Outras sequências ACE2 intimamente relacionadas encontradas foram do pangolim malaio (Manis javanica) com $84,8 \%$ de identidade e coelho europeu (Oryctolagus cuniculus) com 84,8\%. As proteínas ACE2 dos hospedeiros intermediários do SARS-CoV no cachorro-guaxinim (Nyctereutes procyonoides) e da civeta de palmeira mascarada (Paguma larvata) também apresentaram alto grau de conservação em sequência com $83,9 \%$ e $83,5 \%$ de similaridade de sequência, respectivamente. Sequências de cães domésticos (Canis lupus familiaris) e furões domésticos (Mustela putorius furo) exibiram 83,4\% e 82,6\%, respectivamente. O ACE2 dos morcegos das espécies Rhinolophus-sinicus e Hipposideros armiger, conhecidas por abrigar coronavírus relacionados ao morcego SARS, apresentaram similaridades de sequência mais baixas em 80,7\% e 80,5\%, respectivamente (8).

\section{CONCLUSÃO}

O SARS-CoV-2, causador da COVID-19, é responsável pela primeira pandemia conhecida causada por um coronavírus, sendo o SARS-CoV-2 o terceiro vírus desta família a causar infecções fatais em humanos, após o SARS-CoV e o MERS-CoV. É visível o salto de espécies que está associado aos morcegos, visto que o SARS-CoV-2 originou de um reservatório animal, sendo mais provável o morcego, bem como pangolins. Os gatos são hospedeiros suscetíveis ao SARS-CoV-2 humano devido ao grau de semelhança entre as formas humana e felina da ACE2. Os furões também são hospedeiros suscetíveis ao SARS$\mathrm{CoV}-2$ devido às semelhanças na arquitetura de seus respectivos tratos respiratórios. É importante ressaltar que diversos animais estão envolvidos na COVID-19 como reservatórios, hospedeiros e como modelos experimentais.

Ressalta-se que os humanos continuam sendo a fonte de disseminação do SARS-CoV-2 para outros humanos, animais domésticos, silvestres e de produção. A vigilância deste vírus deve ser direcionada para identificar os reservatórios do SARS-CoV-2, bem como outros vírus relacionados que possam serem transmitidos aos seres humanos, além de mais estudos para melhor compreensão da patogênese e hospedeiros.

\section{AGRADECIMENTOS}

Agradeço a todos os autores que contribuíram neste artigo e ao Laboratório de Sanidade Animal de Bauru.

\section{Conflito de interesse}

Declaro que não há conflitos de interesse pelos autores.

\section{Suporte financeiro}

Não houve suporte financeiro para elaboração deste artigo de revisão.

\section{REFERÊNCIAS}

1. Bonilla-Aldana DK, Dhama K, Rodriguez-Morales AJ. Revisiting the one health approach in the context of COVID-19: a look into the ecology of this emerging disease. Adv Anim Vet Sci. 2020;8(3):234-7. doi: http://dx.doi.org/10.17582/journal.aavs/2020/8.3.234.237. 
2. Vale B, Lopes AP, Fontes MC, Silvestre M, Cardoso L, Coelho AC. Bats, pangolins, minks and other animals - villains or victims of SARS-CoV-2? Vet Res Commun. 2021;45(1):1-19. doi: https://doi.org/10.1007/s11259-021-09787-2.

3. Duarte PM. COVID-19: origin of the new coronavirus. Braz J Health Rev. 2020;3(2):3585-90.

4. Tiwari R, Dhama K, Sharun K, Yatoo MI, Malik YS, Singh R, et al. COVID-19: animals, veterinary and zoonotic links. Vet Q. 2020;40(1):169-82. doi: $10.1080 / 01652176.2020 .1766725$.

5. Abdel-Moneim AS, Abdelwhab EM. Evidence for SARS-CoV-2 infectionof animal hosts. Pathogens. 2020;9(7):529. doi: 10.3390/pathogens9070529.

6. Martin PS, Gonçalves SL, Goularte PS, Dias EP, Leonardi AE, Tiezzi DG, et al. História e epidemiologia da COVID-19. ULAKES J Med. 2020;1:11-22.

7. Macedo Júnior AM. Covid-19: calamidade pública. Medicus. 2020;2(1):1-6. doi: http://doi.org/10.6008/CBPC2674-6484.2020.001.0001.

8. Stout AE, André NM, Jaimes JA, Millet JK, Whittaker GR. Coronaviruses in cats and other companion animals: where does SARS-CoV-2/COVID-19 fit? Vet Microbiol. 2020;247:108777.

9. Rodrigues KMMT, Carvalho AAV, Mendonça AC, Carvalho PMG, Vielmo AC. Particularidades da infecção por diferentes estirpes de Coronavirus em animais domésticos e de produção. Rev Desafios. 2020;7 Supl COVID-19:34-7. doi: http://dx.doi.org/ 10.20873/uftsuple2020-8952.

10. Santos WJ, Guiraldi LM, Lucheis SB. Should we be concerned about COVID-19 with nonhuman primates? Am J Primatol. 2020;82:e23158. doi:10.1002/ajp.23158.

11. Oreshkova N, Molenaar RJ, Vreman S, Harders F, Munnink BBO, Honing RWH, et al. SARS-CoV-2 infection in farmed minks, the Netherlands, April and May 2020. Euro Surveill. 2020;25(23):2001005.

12. Shi J, Wen Z, Zhong G, Yang H, Wang C, Huang B, et al. Susceptibility of ferrets, cats, dogs, and Other domesticated animals to SARS-coronavirus-2. Science. 2020;368(6494):1016-20.

13. Schlottau K, Rissmann M, Graaf A, Schön J, Sehl J, et al. Experimental transmission studies of SARS-CoV-2 in fruit bats, ferrets, pigs and chickens. SSRN Electron J. 2020;1:19-21. doi: https://doi.org/10.2139/ssrn.3578792.

14. Zhao S, Musa SS, Lin Q, Ran J, Yang G, Wang W, et al. Estimating the unreported number of novel Coronavirus $(2019-\mathrm{nCoV})$ cases in China in the first half of january 2020: a data-driven modelling analysis of the early outbreak. J Clin Med. 2020;9(2):388. doi: https://doi.org/10.3390/jcm9020388. 
15. Luan J, Jin X, Lu Y, Zhang L. SARS-CoV-2 spike protein favors ACE2 from Bovidae and Cricetidae. J Med Virol. 2020;92(9):1649-56. doi: https://doi.org/10.1002/jmv.25817.

16. Freuling CM, Breithaupt A, Müller T, Sehl J, et al. Susceptibility of raccoon dogs for experimental SARS-CoV-2 infection. bioRxiv. 2020. doi: https://doi.org/ $10.1101 / 2020.08 .19 .256800$

17. McNamara T, Richt JA, Glickman LA. Critical needs assessment for research in companion animals and live stock following the pandemic of COVID-19 in humans. Vector Borne Zoonotic Dis. 2020;20(6):393-405. doi: 10.1089/vbz.2020.2650.

18. Ulrich L, Wernike K, Hoffmann D, Mettenleiter TC, Beer M. Experimental infection of cattle with SARS-CoV-2. Emerg Infect Dis. 2020;26(12):2979-81.

19. Mullick JB, Simmons CS, Gaire J. Animal models to study emerging Technologies against SARS-CoV-2. Cell Mol Bioeng. 2020;13(4):293-303. doi: https://doi.org/10.1007/s12195-020-00638-9.

20. Munster VJ, Feldmann F, Williamson BN, van Doremalen N, Pérez-Pérez L, Schulz J, et al. Respiratory disease in rhesus macaques inoculated with SARS-CoV-2. Nature. 2020;585(7824):268-72.

21. Shan C, Yao YF, Yang ZM, Zhou Y-W, Gao G, Peng Y, et al. Infection with novel coronavirus (SARS-CoV-2) causes pneumonia in the Rhesus Macaques. Cell Res. 2020;30(8):670-7.

22. Osterrieder N, Bertzbach LD, Dietert K, Abdelgawad A, Vladimirova D, Kunec D, et al. Age dependente progression of SARS-CoV-2 infection in Syrian hamsters. Viruses. 2020;12(7):779. doi: https://doi.org/10.3390/v12070779.

23. Chan JF, Zhang AJ, Yuan S, Poon VK-M, Chan CC-S, Lee AC-Y, et al. Simulation of the clinical and pathological manifestations of Coronavirus Disease 2019 (COVID-19) in golden Syrian hamster model: Implications for disease pathogenesis and transmissibility. Clin Infect Dis. 2020;71(9):2428-46.

24. Sia SF, Yan L-M, Chin AWH, Fung K, Choy K-T, Wong AYL, et al. Pathogenesis and transmission of SARS-CoV-2 in golden hamsters. Nature. 2020;583:834-8.

Recebido em: 02/06/2021 Aceito em: 13/08/2021 